\title{
THE RECOVERY PROFILE OF HYPERBARIC BUPIVACAINE AND BUPIVACAINE WITH FENTANYL IN SPINAL ANAESTHESIA
}

\author{
Simeen Usmani1, Jamal Azmat², Farah Nafees ${ }^{3}$, Rahida Hilal ${ }^{4}$
}

${ }_{1}^{1}$ Assistant Professor, Department of Surgery, AKT College, AMU Aligarh, Uttar Pradesh, India. ${ }^{2}$ Assistant Professor, Department of Medicine, AKT College, AMU Aligarh, Uttar Pradesh, India. 3 Postgraduate Scholar, Department of Surgery, AKT College, AMU Aligarh, Uttar Pradesh, India. ${ }^{4}$ Assistant Professor, Department of Surgery, AKT College, AMU Aligarh, Uttar Pradesh, India.

\begin{abstract}
\section{BACKGROUND}

Knowledge of the recovery profile from a spinal anaesthetic is helpful in predicting time to meeting discharge criteria from an ambulatory surgery center. Upper abdominal surgery takes 2 to 3 hours. Which was previously considered inappropriate for the ambulatory setting, surgery is now being performed on outpatients under spinal anaesthesia. Therefore, it is important for anaesthesiologists to know the recovery profile of Bupivacaine and Bupivacaine with Fentanyl. There is always need of search of such a drug combination which reduces the hospital stay of patient with minimal side effects. This study explores the use of long acting local anaesthetic Bupivacaine and Bupivacaine with Fentanyl for upper abdominal surgery.
\end{abstract}

\section{METHODS}

120 patients undergoing upper abdominal surgery were enrolled in a double-blinded clinical trial study. Patients were randomly allocated into two groups. Group A received $17.5 \mathrm{mg}(3.5 \mathrm{ml})$ of Bupivacaine and Group B received Bupivacaine $15 \mathrm{mg}$ and $25 \mu \mathrm{g}$ of Fentanyl $(3.5 \mathrm{ml})$ as intrathecal drug for spinal anaesthesia. Sensory and motor blockade scores, postoperative pain scores and need of analgesic injection 6 and 12 hours after surgery, postoperative voiding time, and the incidence of hypotension, bradycardia, respiratory depression, and nausea and vomiting were recorded. Ambulation time and discharge from hospital were also recorded.

\section{RESULTS}

Complete analgesia (time from injection to first report of pain) time was more in group BF i.e., $146 \pm 8.5$ min, and voiding time was also more in group BF i.e., 10.3 hours (618 $34 \mathrm{~min}$ ), and 3\% patients developed pruritus postoperatively. The average time of discharge was same in both groups but need of analgesic was less in group B. Patients in group BF were more comfortable during post-operative period except 2 patients who develops pruritus.

\section{CONCLUSIONS}

Bupivacaine with intrathecal fentanyl $25 \mu \mathrm{g}$ produces a satisfactory surgical block, significantly decreases the need of analgesic supplementation, but increases the voiding time. early ambulation occurs in this group. There are no side effect of intrathecal fentanyl. It is very good for patients. Thus, overall effect of Bupivacaine and Fentanyl is superior to Bupivacaine alone, apart from positive effects of fentanyl, it decreases the requirement of bupivacaine and has no side effects.

\section{KEY WORDS}

Bupivacaine, Fentanyl, Ambulatory Surgery

HOW TO CITE THIS ARTICLE: Usmani S, Azmat J, Nafees F, et al. The recovery profile of hyperbaric bupivacaine and bupivacaine with fentanyl in spinal anaesthesia. J. Evolution Med. Dent. Sci. 2019;8(24):1945-1948, DOI: 10.14260/jemds/2019/427

\section{BACKGROUND}

Knowledge of the recovery profile from a spinal anaesthetic is helpful in predicting time to meeting discharge criteria from an ambulatory surgery center. Upper abdominal surgery takes 2 to 3 hours. Which was previously considered inappropriate for the ambulatory setting, surgery is now being performed on outpatients under spinal anaesthesia. Therefore, it is important for anaesthesiologists to know the recovery profile of Bupivacaine and Bupivacaine with Fentanyl. Previous work has evaluated spinal local

'Financial or Other Competing Interest': None.

Submission 23-04-2019, Peer Review 03-06-2019,

Acceptance 10-06-2019, Published 17-06-2019.

Corresponding Author:

Jamal Azmat,

\#54, Sagar Housing Complex,

Anoop Shaher Road,

Near FM Tower, ADF, Aligarh, Uttar Pradesh, India.

E-mail: jamazp54@gmail.com

DOI: $10.14260 /$ jemds $/ 2019 / 427$ anaesthetic duration and recovery in terms of sensory regression to a specific dermatome,1,2 time to return of the micturition reflex, ${ }^{3}$ or time to supplemental narcotic requirement for pain. 4

The ability of a subject to flex at the hip, extend the knee and plantar flex the ankle/big toe have been used as an endpoint to analyse recovery from motor blockade. 5 However, none of these criteria are used to determine eligibility for discharge from an ambulatory surgery center. Surgical procedures previously considered too lengthy for the ambulatory surgery setting are now being performed during spinal anaesthesia. The complete recovery profile of Bupivacaine and Bupivacaine with Fentanyl are now of interest but are less available in the literature. This study was conducted to compare times to need of analgesic requirement during and surgery, and postoperatively, any hemodynamic problem like hypotension, bradycardia, nausea, vomiting, respiratory depression, and pruritus were noted. Time of patient's ambulation, spontaneous voiding time and discharge from hospital were also noted. 


\section{METHODS}

This study was conducted at A. K. Tibbiya College hospital over the period of one year. After receiving approval from institutional ethical committee, and a written consent were taken from all patients. 60 patients of ASA 1 and 2 between age of $18-65$ years and weight of 45 to $90 \mathrm{~kg}$ were scheduled for upper abdominal surgery, underwent spinal anaesthesia. Exclusion criteria include, patient having cardiac problem, uncontrolled diabetes and hypertension and use of alcohol addiction and sedative drugs. PAC was done and Tab clonazepam $(0.25 \mathrm{mg}$ ) was given to all patients, night before surgery. On arrival of patient into operating room ECG, $\mathrm{SpO}_{2}$, non-invasive BP were monitored, all patients were preloaded with $5-10 \mathrm{ml} / \mathrm{kg}$ of ringer lactate before spinal anaesthesia. Under all aseptic precautions, after infiltration of local anaesthesia, Lumber puncture were performed in sitting position through midline approach. Patient were randomly divided into two groups. Group A received $17.5 \mathrm{mg}$ ( $3.5 \mathrm{ml}$ ) of Bupivacaine. Group BF received $15 \mathrm{mg}$ of Bupivacaine and 25 $\mu \mathrm{g}$ of Fentanyl $(3.5 \mathrm{ml})$ by volume. After spinal anaesthesia patient were immediately placed in supine position with head end tilted by 15 degrees and $2 \mathrm{~L} / \mathrm{min}$ of oxygen was given through Hudson mask.

The blinded observer recorded the time of spinal anaesthesia and time of onset of motor block. Sensory block was assessed by using analgesia to pin prick by blunt tip needle. The investigator moved the safety pin from cauded to cephalad. Motor block was assessed by using modified Bromage scale which are mentioned as under. The time to reach $\mathrm{T}_{5}$ dermatome sensory block were recorded. All duration of sensory and motor block were calculated, considering the time of injection as time zero. Pulse and noninvasive blood pressure were measured every 5 minutes for first 30 , minute and there after every 10 minutes.

If the blood pressure fell below $90 \mathrm{mmHg}$, injection Mephentermine was given, bradycardia defined as heart rate below $<60$ beat/ minute and were treated with Atropine. Incidence of nausea, vomiting, shivering, pruritus and sedation given were recorded. $\mathrm{SpO}_{2}$ was monitored continuously in the operating room. After completion of surgery patient were shifted to ward and nurses on duty were instructed to observe and note the time of analgesic requirement, nausea, vomiting, pruritus, spontaneous voiding and leg movements.

\section{Modified Bromage Scale 5}

Grade $0=$ no block, full straight leg raise possible.

Grade 1 = inability to elevate extended leg (Able to flex knee).

Grade 2 = inability to flex knee (Able to move foot only).

Grade $3=$ inability to flex ankle.

Grade $4=$ Complete motor paralysis.

\section{Statistical Analysis}

In this study, 120 patient receiving spinal anaesthesia using hyperbaric Bupivacaine (17 mg), and Bupivacaine with fentanyl (15 mg + $25 \mu \mathrm{g}$ ) underwent upper abdominal sugary. Demographic data were analysed using student t- test. The incidence of hypotension, bradycardia, analgesic requirement, nausea, vomiting, were compared using Chi square test. Student $t$-test was used to compare the variables, eg, time of urination, and ambulation. And hospital stay time.

\section{RESULTS}

The two groups were comparable with respect to ASA status, age, weight, height, and surgical time as shown in table I.

\begin{tabular}{|c|c|c|c|c|c|c|c|c|}
\hline & \multirow{2}{*}{ Age } & \multicolumn{2}{|c|}{ Sex } & \multirow{2}{*}{ Weight } & \multirow{2}{*}{ Height } & $\begin{array}{c}\text { Surgical } \\
\text { time }\end{array}$ & \multicolumn{2}{|c|}{ ASA } \\
\cline { 7 - 9 } & & $\mathbf{M}$ & $\mathbf{F}$ & $\mathbf{I}$ & $\mathbf{I I}$ \\
\hline $\begin{array}{c}\text { Group A } \\
60\end{array}$ & $\begin{array}{c}40.68 \pm \\
16.3\end{array}$ & 16 & 44 & $64.6 \pm 11.41$ & $\begin{array}{c}156 \pm \\
3.8\end{array}$ & $35.5 \pm 12.2$ & 50 & 48 \\
\hline $\begin{array}{c}\text { Group BF } \\
60\end{array}$ & $41.52 \pm \mathrm{i} 2.3$ & 19 & 41 & $65.38 \pm 14.3$ & $155 \pm 2.42$ & $30.15 \pm 10.5$ & 10 & 12 \\
\hline
\end{tabular}

Table I. Demographic Profile of Two Groups with Mean S.D. value

Group A and Group B were comparable regarding demographic variables, type and duration of surgery.

\begin{tabular}{|c|c|c|c|c|}
\hline 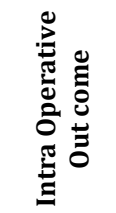 & 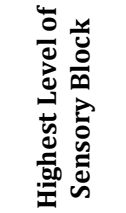 & 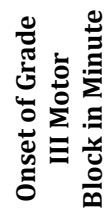 & 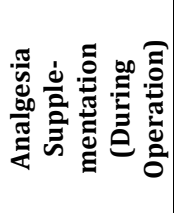 & 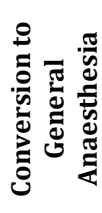 \\
\hline $\begin{array}{l}\text { Group A } \\
(n=60)\end{array}$ & $\mathrm{T}_{5}\left(\mathrm{~T}_{4}-\mathrm{T}_{6}\right)$ & $5 \pm 2.1$ & $24(40 \%)$ & 2 \\
\hline $\begin{array}{c}\text { Group BF } \\
(n=60)\end{array}$ & $\mathrm{T}_{5}\left(\mathrm{~T}_{4}-\mathrm{T}_{6}\right)$ & $6 \pm 1.1$ & $13(21 \%)$ & 0 \\
\hline
\end{tabular}

Table 2. Characteristic of Motor and Sensory Block

Values are mean \pm SD and in percentage. $p<0.05$ considered significant (unpaired ' $t$ ' test). No statistically significant difference in motor and sensory block

\begin{tabular}{|c|c|c|c|c|c|c|}
\hline & 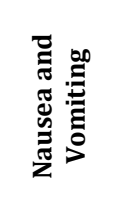 & 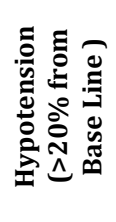 & 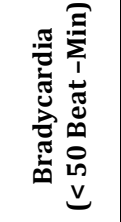 & 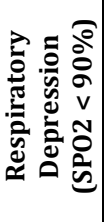 & $\stackrel{\mathscr{Z}}{\Xi}$ & 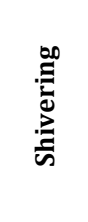 \\
\hline $\begin{array}{l}\text { Group A } \\
(n=60)\end{array}$ & $24(40 \%)$ & $19(31 \%)$ & $30(50 \%)$ & 0 & 0 & $4(6 \%)$ \\
\hline $\begin{array}{c}\text { Group BF } \\
(n=60)\end{array}$ & 15 (25\%) & $11(18 \%)$ & $34(56 \%)$ & $3(5 \%)$ & $2(3 \%)$ & 0 \\
\hline
\end{tabular}

Table 3. Post-Operative Side-Effects and Complications in Patients

Values are in numbers of the patients and percentage (\%). Respiratory depression $\left(\mathrm{SpO}_{2}<90 \%\right)$, and pruritus were more in group $\mathrm{BF}$, most operative monitoring is necessary.

\begin{tabular}{|c|c|c|c|c|}
\hline & 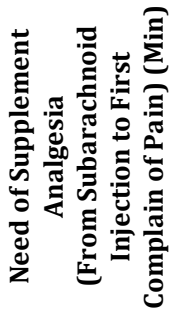 & 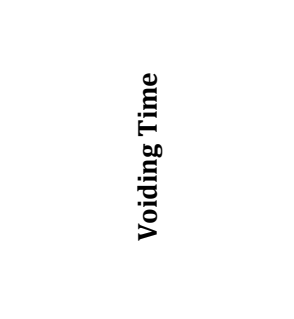 & 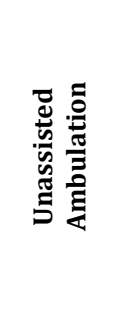 & 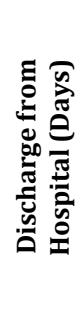 \\
\hline $\begin{array}{l}\text { Group A } \\
(\mathrm{n}=60)\end{array}$ & $120 \pm 3.5$ & 8.5 hours $(510 \pm 15 \mathrm{~min})$ & 24 hours & 2 \\
\hline $\begin{array}{c}\text { Group BF } \\
(n=60)\end{array}$ & $146 \pm 8.5$ & 10.3 hours $(618 \pm 34 \mathrm{~min})$ & 18 hours & 2 \\
\hline
\end{tabular}

Table 4. Comparison of Recovery Parameters of the Two Groups

Voiding time, is more in group $\mathrm{BF}$, and need of analgesic injection is less in group BF which is statically significant, $p$ value $<0.05$ was considered statically significant.

\section{DISCUSSION}

Bupivacaine, an amide type of local anaesthetic, has high potency, slow onset (5-8 minutes) and long duration of 
action (1.5-2 hours). Administration of fentanyl intrathecally is an established method for Intraoperative anaesthesia and to supplement post-operative analgesia. Fentanyl acts on opioid receptors or other nonspecific binding sites in the spinal cord. Result of this study showed that Fentanyl $25 \mu \mathrm{g}$ prolongs the duration of Bupivacaine induced sensory blockade. This suggests a potential synergism between Fentanyl and Bupivacaine, as reported by Wang et al. ${ }^{6}$ Advantage of using intrathecal fentanyl is its extremely rapid onset of action. Analgesia has been reported to occur within 5-10 minute. In our study this time is $6 \pm 1.1$ minute. BenDavid et $\mathrm{al}^{7}$ showed that fentanyl added to bupivacaine could reduce the dose of local anaesthetic to $5 \mathrm{mg}$ and still provide sufficient analgesia for arthroscopy. We did not find any studies in the literature in which small doses of plain hyperbaric bupivacaine were used for outpatient herniorrhaphy, and there is only one study in combination with fentanyl ${ }^{8}$. In that investigation, fentanyl was given in a dose of $25 \mu \mathrm{g}$ as an adjuvant to $9-11.25 \mathrm{mg}$ of bupivacaine. This combination produced good analgesia, but we need motor block up to T5 so by giving small dose as mentioned above we cannot able to perform surgery. In spite of giving 3$5 \mathrm{ml}$ of Bupivacaine $40 \%$ of patient in group A and $21 \%$ of patient in group BF need analgesic supplements but it is lesser in group $\mathrm{BF}$

Epidurally administered fentanyl in doses of 50-100 microgram has been shown to provide postoperative analgesia of 3-4 duration. ${ }^{9}$ This was similar to our duration of effective analgesia, following $25 \mu \mathrm{g}$ dose of subarachnoid fentanyl. The patient of group A experienced more pain as compare to group B. time of giving analgesic injection was$120 \pm 3.5$-min in group A and -146. $\pm 8.5-$ min in group BF. Group BF patients were more comfortable in our study, and that result was similar to most of the studies.

One of the biggest limitations of our study is that patient was not interested in ambulation on the day of surgery because of psychological fear of pain and opening of stitches. In our study, two patients belong to group BF, receiving $25 \mu \mathrm{g}$ fentanyl complain of pruritus which is similar to the report of Hunt et al. ${ }^{10}$ We did not observe significant respiratory depression or sedation except in one patient. Gang $\mathrm{T}$ J et al observed that Fentanyl $20 \mu \mathrm{g}$ was added to Bupivacaine, it reduces Intraoperative nausea and vomiting and prolongs anaesthesia. 11,12 In our study $40 \%$ of patients from group A and $25 \%$ patients from group BF felt nausea and having vomiting. It is reduced in group $\mathrm{BF}$

Intra operative nausea and vomiting occurs in as many as (30) $\%$ of gallbladder surgery. ${ }^{13}$ it was more in group A $40 \%$ and $25 \%$ in group B it could be mainly related to peritoneal traction. M Anullang et $\mathrm{al}^{14}$ and Dahlgren et $\mathrm{al}^{9}$ observation is same. For cesarean section intrathecal dose of hyperbaric Bupivacaine is 12 to $15 \mathrm{mg}$. Cesarean delivery requires traction of peritoneum and handling of intraperitoneal organs, resulting in intra operative visceral pain. With higher doses of hyperbaric bupivacaine, incidence of intraoperative visceral pain associated with higher blocks is reduced.

Goel et $\mathrm{al}^{15}$ found $12.5 \mu \mathrm{g}$ Fentanyl provide better surgical anaesthesia but increased urinary retention, which is a significant side effect of spinal opioids, but fentanyl appears to have a more favorable result, Liu et al 16 found no increase in time of first voiding. Ben David et $\mathrm{al}^{7}$ reported no significant difference in time to urination with addition of 10 $\mu \mathrm{g}$ IT fentanyl. In present study group A have taken 8.5 hours $(510 \pm 15 \mathrm{~min})$ and group BF had taken 10.3 hours $(618 \pm 34$ min). Thus, there was significant increase in time in group BF. Manjulata et al ${ }^{17}$ study showed voiding time was $330 \mathrm{~min}$, in our study the voiding time of group A $510 \pm 15$ min and Group $\mathrm{BF}$ was $618 \pm 34 \mathrm{~min}$. which were significantly higher as compare to other studies. It could be due to increase volume of bupivacaine used for the reliability of the block. Gurbet et $\mathrm{al}^{18}$ found that $25 \mu \mathrm{g}$ IT fentanyl reduced the analgesic requirement similar to our study. Belzarana ${ }^{19}$ used 0.5 or $0.75 \mu \mathrm{g} / \mathrm{kg}$ IT fentanyl for caesarean delivery and Singh et al used $25 \mu \mathrm{g}$ IT fentanyl for lower extremity surgery.

According to our experience if Bupivacaine $15 \mathrm{mg}$ is diluted with $0.5 \mathrm{ml}$ of saline to make a volume of $3.5 \mathrm{ml}$ often results in failed block because we are giving high spinal and performing gall bladder surgery in spinal anaesthesia. At our centre the gall bladder surgery are performed under spinal anaesthesia as there is lack of staff for post-operative monitoring cost is another consideration as our centre caters patients from very poor socio economic status.

The ability of a subject to flex at the hip, extend the knee and planter flex the ankle, big toe have been used as an end point to analyse recovery from motor blockade, 5 but we cannot discharge the patients on that basis, sometime due to mild pain and fear to open the stitches, most of the patients did not cooperate. The time taken by patient to, ambulate and completely resolve analgesia after spinal anaesthesia with Group A and Group BF were equal, the cause could be that patient were not interested to ambulate on day of surgery and at night we cannot insist the patient to ambulate, and next day of surgery all patients were able to ambulate but they need support only due to fear.

\section{CONCLUSIONS}

Bupivacaine with intrathecal fentanyl $25 \mu$ g produces a satisfactory surgical block, significantly decreases the need of analgesic supplementation, but increases the voiding time. early ambulation occurs in this group. There are no side effect of intrathecal fentanyl. It is very good for patients. Thus, overall effect of Bupivacaine and Fentanyl is superior to Bupivacaine alone, apart from positive effects of fentanyl, it decreases the requirement of bupivacaine and has no side effects.

\section{REFERENCES}

[1] Pflug EA, Aasheim GM, Beck HA. Spinal anaesthesia: bupivacaine versus tetracaine. Anaesth Analg 1976;55(4):489-92.

[2] Rocco AG, Francis DM, Wark JA, et al. A clinical doubleblind study of dibucaine and tetracaine in spinal anaesthesia. Anesth Analg 1982;61(2):133-7.

[3] Axelsson K, Mollefors K, Olsson J, et al. Bladder function in spinal anaesthesia. Acta Anesthesiol Scand 1985;29(3):315-21.

[4] Moore DC. Spinal anaesthesia: bupivacaine compared with tetracaine. Anesth Analg 1980;59(10):743-50.

[5] Bromage PR. A comparison of the hydrochloride and carbon dioxide salts of lidocaine and prilocaine in epidural analgesia. Acta Anaesthesiol Scand Suppl 1965;16:55-69. 
[6] Wang C, Chakrabarti MK, Whitwam JG. Specific enhancement by fentanyl of the effects of intrathecal bupivacaine on nociceptive afferent but not on sympathetic efferent pathways in dogs. Anesthesiology 1993;79(4):766-73.

[7] Ben-David B, Solomon E, Levin H, et al. Intrathecal fentanyl with small-dose dilute bupivacaine: better anaesthesia without prolonging recovery. Anesth Analg 1997;85(3):560-5.

[8] Song D, Greilich NB, White PF, et al. Recovery profiles and costs of anaesthesia for outpatient unilateral inguinal herniorrhaphy. Anesth Analg 2000;91(4):876-81.

[9] Dahlgren G, Hultstrand C, Jakobsson J, et al. Intrathecal sufentanil, fentanyl, or placebo added to bupivacaine for cesarean section. Anesth Analg 1997;85(6):128893.

[10] Hunt CO, Naulty JS, Bader AM, et al. Perioperative analgesia with subarachoid fentanyl bupivacaine for Caesarean delivery. Anesthesiology 1989;71(4):53540.

[11] Gan TJ. Postoperative nausea and vomiting - can it be eliminated? Journal of the American Medical Association 2002;287(10):1233-6.

[12] Akerman B, Arwestrom E, Post C. Local anaesthetics potentiate spinal morphine antinociception. Anesth Analg 1988;67(10):943-8.
[13] Pedersen H, Santos AC, Steinberg ES, et al. Incidence of visceral pain during cesarean section: the effect of varying doses of spinal bupivacaine. Anaesthesia \& Analgesia 1989;69(1):46-9.

[14] Manullang TR, Viscomi CM, Pace NL. Intrathecal fentanyl is superior to intravenous ondansetron for prevention of perioperative nausea during caesarean delivery with spinal anaesthesia. Anesth Analg 2000;90(5):1162-6.

[15] Goel S, Bhardwaj N, Grover VK. Intrathecal fentanyl added to intrathecal bupivacaine for day case surgery: a randomized study. Eur Journal of Anaesthesia 2003;20(4):294-7.

[16] Liu S, Chiu AA, Carpenter RL, et al. Fentanyl prolongs lidocaine spinal anaesthesia without prolonging recovery. Anesth Analg 1995;80(4):730-4.

[17] Manjulata T, Lakra AM, et al. Hyperbaric bupivicaine and 2-chloroprocaine for spinal anaesthesia in outpatient procedures: a comparative study. Indian Journal of Applied Research 2018;8(6).

[18] Gurbet A, Turker G, Girgin NK, et al. Combination of ultra-low dose bupivacaine and fentanyl for spinal anaesthesia in out-patient anorectal surgery. The Journal of International Medical Research 2008;36(5):964-70.

[19] Belzarena SD. Clinical effects of intrathecally administered fentanyl in patients undergoing cesarean section. Anesth Analg 1992;74(5):653-7. 